
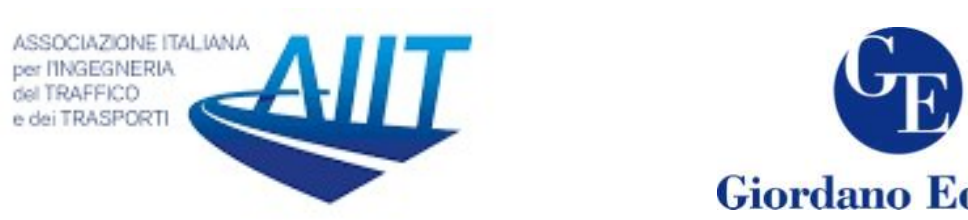

Giordano Editore

\title{
Effectiveness of unconventional roundabouts in the design of suburban intersections
}

\author{
Donato Ciampa ${ }^{1}$, Maurizio Diomedi ${ }^{2}$, Fernando Giglio ${ }^{3}$, \\ Saverio Olita $^{1 *}$, Umberto Petruccelli ${ }^{2}$, Carlo Restaino ${ }^{3}$ \\ ${ }^{1}$ Assistant Professor, School of Engineering, University of Basilicata \\ ${ }^{2}$ Associate Professor, School of Engineering, University of Basilicata \\ ${ }^{3}$ Engineer PE, School of Engineering, University of Basilicata
}

\begin{abstract}
The paper focuses on the use of non-conventional roundabouts, such as turbo-roundabouts and flowerroundabouts, for the reduction of both functional and safety critical issues. The aim is to evaluate the effectiveness of non-conventional design schemes compared to conventional solutions through the implementation of vehicular traffic microsimulation techniques and swept path analysis. The work proposes two case studies in suburban areas characterized by the presence of road intersections affected by high traffic criticality. The study compares the performance in terms of average speed, queues length, time loss, vehicle manoeuvring size, etc., between the actual state and two design solutions, respectively conventional and non-conventional. The results obtained highlight the effectiveness of the non-conventional schemes adopted for both the improvement of traffic and safety parameters and for the containment of polluting emissions into the atmosphere. The work also proposes a methodological approach that can be pursued by the road designer, for the choice between alternative design solutions of conventional and non-conventional roundabout intersections.
\end{abstract}

Keywords: Turbo-roundabout, Flower-roundabout, Microsimulation, Swept path analysis

\section{Introduction}

In the past few years, scientific research in road infrastructure field has been oriented towards the development of new types of road intersections, with a perspective of increasing their capacity and improving their safety conditions. Among the most interesting solutions, there are schemes similar to traditional roundabouts, even if with quite different modes of operation [1,2]. These are, in particular, turbo-roundabouts and flower-roundabouts (unconventional roundabouts) which, due to their peculiarities, are increasingly used in Europe (particularly in the Netherlands, Slovenia and Germany) [3, 4] to remove black spots from the road network or to improve the performance of already in-service intersections $[5,6]$.

The aim of the paper is to evaluate the effectiveness of non-conventional design schemes compared to conventional solutions using vehicle traffic microsimulation and

\footnotetext{
*Corresponding author: Saverio Olita (saverio.olita@unibas.it)
} 
swept path analysis tools. The work, in particular, examines two case studies in which road intersections, at the moment, present highly criticalities both in terms of function and safety. The study was divided into the analysis of the actual state, the design of conventional solutions and then the design of unconventional roundabout intersections.

The turbo-roundabout is a particular type of roundabout intersection where the lanes are delimited both by road markings and by kerbs installed on the branches and on the ring carriage; this determines the specialization of the lanes at the entrances which are only subject to pre-established turning manoeuvres. From an operational point of view, unlike in conventional roundabouts where vehicles reach the "give away" line in pairs, and only later they take the trajectory to exit one of the remaining arms of the junction, in turbo-roundabouts users are forced to pre-select the desired lane a few tens of meters before entering the ring, precisely because of the physical separation of the lanes. The term "turbo" refers to the planimetric configuration of the roundabout, similar to a turbine, and to the "vortex-like" vehicular trajectories resulting from the particular geometry of the intersection.

The main advantages of a turbo-roundabout, compared to conventional schemes, are listed below [7-10]:

- reduction of conflict points: as it is well known, for a 4-arm intersection, the rotational circulation pattern reduces the conflict points numbers from 32 to 16 , while with the turbo-roundabout the conflict points drop to 10 , located only at the entry points;

- reduction of travel speeds: given its particular geometric conformation, this scheme reduces the travel speeds of the spiral/ring and the speed of approach to the intersection;

- increase in capacity: the capacity of the intersection is increased on average by $15 \%$, with a reduction in delays on each single branch;

- reduction in the number of accidents: the number of accidents is reduced by approximately $50 \%$, with a consequent reduction in the number of injured persons $(30 \%)$.

The flower-roundabouts, roundabouts with "depressed" lanes for right turns, are particularly suitable for improving the intersection from an environmental and functional point of view. However, there are also advantages from a safety point of view. Specifically, the flower-roundabout does not have any crossing conflict points while maintaining the same occupation of the two-lane roundabouts. One of the fundamental characteristics of roundabouts with "depressed" lanes for right turns is the separation of traffic with a consequent decrease in vehicle flow on the roundabout ring carriage, which is only used by vehicles that have to go straight ahead or turn left $[11,12]$.

The separation of the vehicle flows makes one single lane on the roundabout ring sufficient: unlike the case of turbo-roundabouts, there are no crossing conflict points and, unlike two-lane roundabouts, there are no exchange conflict points either. The exchange conflict points move from the roundabout ring to the road section before entering the roundabout; therefore, this is a safer solution for traffic circulation safety [13].

\section{Design and Standard references}

The first guidelines for the geometrical design of turbo-roundabout were published in 2008 by the Dutch Information and Technology Platform CROW [14]. Since 2008 many European countries have started to develop national regulations [15-18]. Overseas 
regulations are still under development. In this work, reference has been made to the most recent regulations and in particular to the German ones [16].

Generally, for the design of a turbo-roundabout, schemes, proposed by the different regulations/guidelines, called "turboblocks", are used. Once the geometry has been defined, the design moves on to the definition of the central island and the surmountable dividing lines of the lanes.

The "turbine" shape of the central island is obtained through arcs of circumference of different center and radius inserted in predetermined blocks. The geometric construction is divided into the following distinct phases (Figure 1) [19]:

- the intersection center (intersecting road axes) is identified;

- the lane and the separating strip width are chosen, the sum of which is equal to $\Delta \mathrm{R}$, which corresponds to the distance between the centers $\mathrm{C}_{1}$ and $\mathrm{C}_{2}$;

- the centers $C_{1}$ and $C_{2}$ are positioned symmetrically with respect to the point of intersection of the road axes;

- chosen the value of the first radius $R_{1}$, the other values of the radii $\left(R_{2}\right.$ and $\left.R_{3}\right)$ are defined by the following relation $R_{n}=R_{n-1}+\Delta R$.

The curvature radii values of the central island shall be chosen so as to ensure that the speed of the roundabout is less than or equal to $40 \mathrm{~km} / \mathrm{h}$.

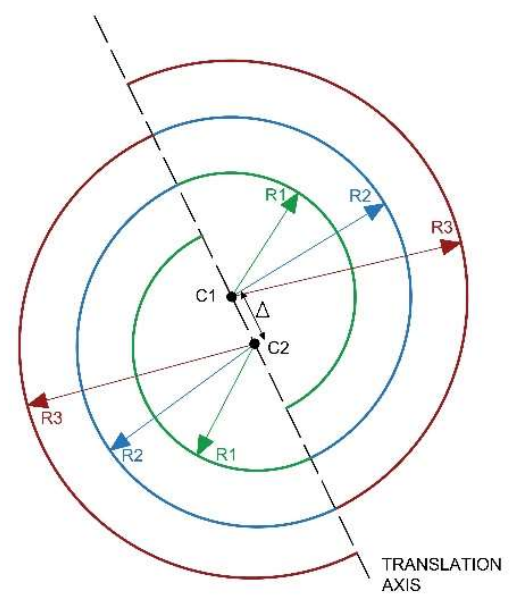

Figure 1: Turbo-roundabout circulating carriageway layout.

The turbo-roundabout island is composed of a surmountable boundary area and a central part that cannot be accessed. The Dutch Standard provides for a surmountable area not less than $5 \mathrm{~m}$ wide, as this can ensure that vehicles with a length of more than $22 \mathrm{~m}$ can pass through the inner lane. In the other Standards the surmountable zone is defined as an emergency lay-by that, in some cases, can be used by damaged vehicles. In this case the width of the surmountable zone varies from $2.0 \mathrm{~m}$ to $2.5 \mathrm{~m}$.

For what concerns the not surmountable area, the Dutch guidelines define this area as that part of the roundabout where it is possible to insert the vertical signs necessary for traffic and any architectural works, while maintaining the visibility criteria established by local regulations; according to the other regulations, already mentioned above, this space is irrelevant for traffic and is defined as "redundant roundabout area" [20].

The entrance to the inner lane can be designed in two ways: flat or spiral entrance; in the Dutch guidelines, flat construction is preferred to spiral construction because it is more impactful and less ambiguous for vehicles arriving at the roundabout. In the Croatian guidelines, all the illustrated traffic schemes have access to the inner lane in a 
spiral shape without any indication on its design. One aspect that should be emphasized is that, in all cases, it is taken into account that the shape of the central island influences the speed of the "fastest" vehicle entering the roundabout, which is of course something that should be kept under control as it increases the safety of the intersection [20].

The geometrical design of the flower-roundabouts, instead, is based on the following 4 phases starting from the basic geometry of a normal 2-lane roundabout [12]:

- insertion of an additional lane towards the center of the roundabout;

- extension of the entrance and exit lines;

- extension of the traffic islands along the entrance/exit legs towards the center of the roundabout;

- arrangement of redundant surfaces in green flowerbeds.

\section{Case studies and analysis methodology}

In order to appreciate the infrastructural improvement related to the use of the abovementioned unconventional circulation schemes, two case studies have been developed that implement respectively: the turbo-roundabout scheme and the flower-roundabout scheme. The two intersections are located in the industrial area of the city of Potenza (Italy) and present different critical points. Specifically, the first one (case study 1) is affected during peak hours by light traffic flows and at some times by heavy traffic flows (Figure 2a). The second intersection (case study 2) is affected throughout the day by heavy vehicular traffic due to the presence of industrial activities in the nearby area (Figure 3a).

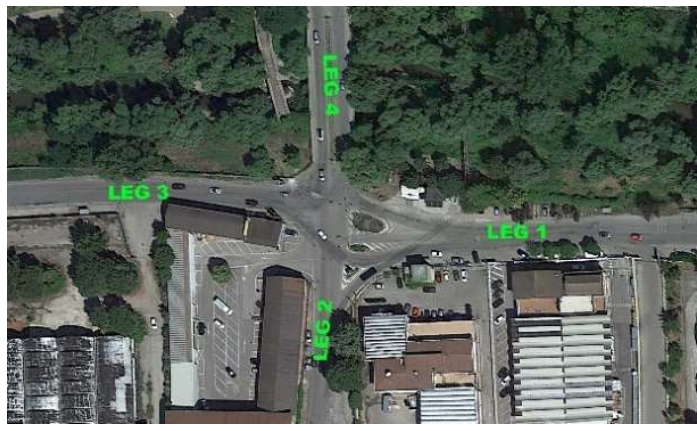

(a)

Figure 2: Intersection 1.

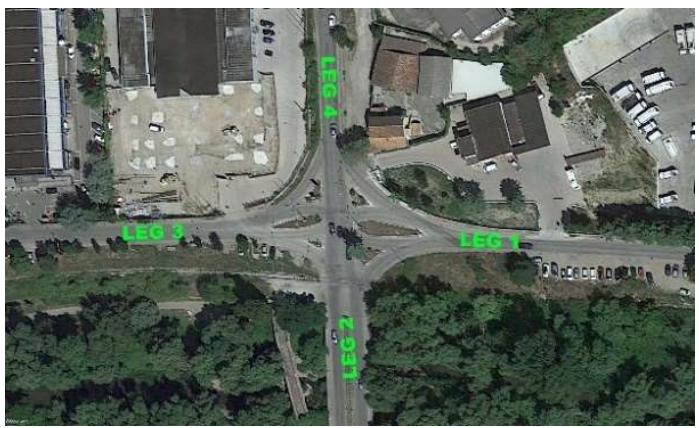

(a)

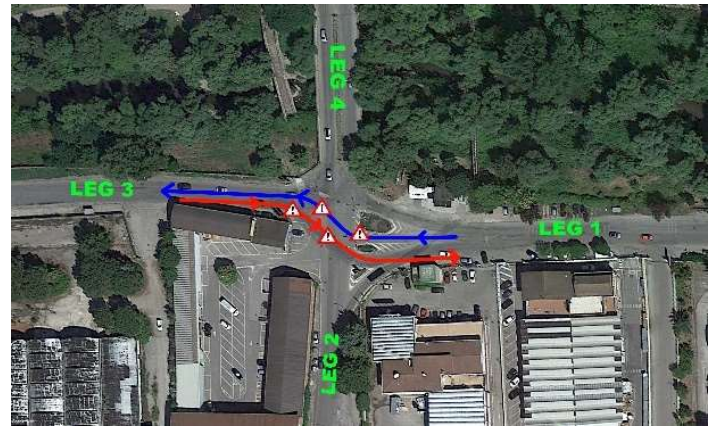

(b)

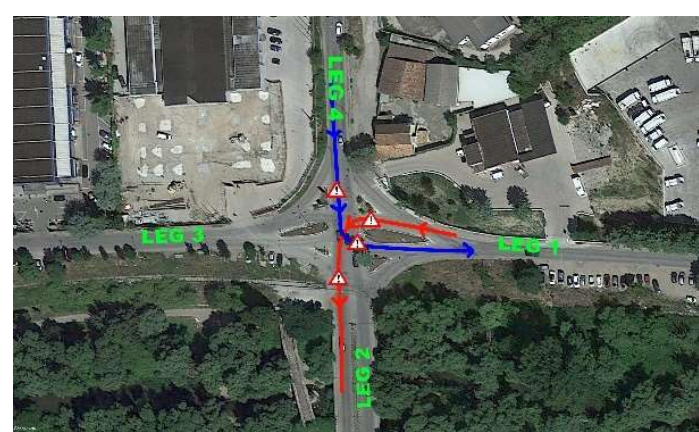

(b)

Figure 3: Intersection 2. 
The starting point, for both cases, was the study of critical issues and the survey of traffic flows that allowed the definition of the relative O/D matrices. The survey of traffic flows was particularly accurate at peak times, i.e. during the 8-9 am, 1-2 pm and 6-7 pm hours. The surveys were conducted for several days and in several weeks of October and November 2018. The O/D matrices (Table 1) were constructed summing the mean numbers of vehicles observed on different paths with reference to the four time periods of 15 minutes forming each of the three peak hours above mentioned (Table 2).

Table 1: O/D matrices - mean values (veh/h)

\begin{tabular}{|c|c|c|c|c|c|c|c|c|c|c|c|}
\hline \multicolumn{6}{|c|}{ Intersection 1} & \multicolumn{6}{|c|}{ Intersection 2} \\
\hline \multicolumn{6}{|c|}{$8: 00-9: 00 / 13: 00-14: 00 / 18: 00-19: 00$} & \multicolumn{6}{|c|}{$8: 00-9: 00 / 13: 00-14: 00 / 18: 00-19: 00$} \\
\hline$L E G$ & 1 & 2 & 3 & 4 & Tot & $L E G$ & 1 & 2 & 3 & 4 & Tot \\
\hline 1 & 0 & 52 & 27 & 54 & 133 & 1 & 0 & 19 & 82 & 149 & 235 \\
\hline 2 & 109 & 0 & 46 & 176 & 331 & 2 & 38 & 0 & 42 & 55 & 135 \\
\hline 3 & 17 & 40 & 0 & 21 & 78 & 3 & 91 & 26 & 0 & 127 & 244 \\
\hline 4 & 33 & 169 & 94 & 0 & 296 & 4 & 170 & 31 & 60 & 0 & 261 \\
\hline Tot & 159 & 261 & 167 & 251 & 838 & Tot & 299 & 76 & 184 & 331 & 890 \\
\hline
\end{tabular}

Table 2: Mean number of vehicles for each of four time periods (veh/15min)

\begin{tabular}{|c|c|c|c|c|c|c|c|c|c|c|c|}
\hline \multicolumn{6}{|c|}{ Intersection 1} & \multicolumn{6}{|c|}{ Intersection 2} \\
\hline \multicolumn{6}{|c|}{$8: 00-8: 15 / 13: 00-13: 15 / 18: 00-18: 15$} & \multicolumn{6}{|c|}{$8: 00-8: 15 / 13: 00-13: 15 / 18: 00-18: 15$} \\
\hline$L E G$ & 1 & 2 & 3 & 4 & Tot & $L E G$ & 1 & 2 & 3 & 4 & Tot \\
\hline 1 & 0 & 12 & 4 & 14 & 30 & 1 & 0 & 2 & 13 & 37 & 52 \\
\hline 2 & 28 & 0 & 12 & 47 & 87 & 2 & 10 & 0 & 10 & 14 & 34 \\
\hline 3 & 4 & 8 & 0 & 3 & 15 & 3 & 20 & 6 & 0 & 36 & 62 \\
\hline 4 & 7 & 41 & 24 & 0 & 72 & 4 & 40 & 8 & 13 & 0 & 61 \\
\hline Tot & 39 & 61 & 40 & 64 & 204 & Tot & 70 & 16 & 36 & 87 & 209 \\
\hline \multicolumn{6}{|c|}{$8: 15-8: 30 / 13: 15-13: 30 / 18: 15-18: 30$} & \multicolumn{6}{|c|}{$8: 15-8: 30 / 13: 15-13: 30 / 18: 15-18: 30$} \\
\hline$L E G$ & 1 & 2 & 3 & 4 & Tot & $L E G$ & 1 & 2 & 3 & 4 & Tot \\
\hline 1 & 0 & 14 & 7 & 12 & 33 & 1 & 0 & 3 & 15 & 35 & 53 \\
\hline 2 & 29 & 0 & 9 & 47 & 85 & 2 & 12 & 0 & 9 & 16 & 37 \\
\hline 3 & 5 & 9 & 0 & 6 & 20 & 3 & 25 & 3 & 0 & 34 & 62 \\
\hline 4 & 12 & 39 & 22 & 0 & 73 & 4 & 37 & 9 & 16 & 0 & 62 \\
\hline Tot & 46 & 62 & 38 & 65 & 211 & Tot & 74 & 15 & 40 & 85 & 214 \\
\hline \multicolumn{6}{|c|}{$8: 30-8: 45 / 13: 30-13: 45 / 18: 30-18: 45$} & \multicolumn{6}{|c|}{$8: 30-8: 45 / 13: 30-13: 45 / 18: 30-18: 45$} \\
\hline$L E G$ & 1 & 2 & 3 & 4 & Tot & $L E G$ & 1 & 2 & 3 & 4 & Tot \\
\hline 1 & 0 & 13 & 12 & 14 & 39 & 1 & 0 & 6 & 22 & 47 & 75 \\
\hline 2 & 26 & 0 & 17 & 49 & 92 & 2 & 10 & 0 & 8 & 15 & 33 \\
\hline 3 & 4 & 13 & 0 & 9 & 26 & 3 & 27 & 5 & 0 & 30 & 62 \\
\hline 4 & 7 & 43 & 24 & 0 & 74 & 4 & 45 & 5 & 19 & 0 & 69 \\
\hline Tot & 37 & 69 & 53 & 72 & 231 & Tot & 82 & 16 & 49 & 92 & 239 \\
\hline \multicolumn{6}{|c|}{$8: 45-9: 00 / 13: 45-14: 00 / 18: 45-19: 00$} & \multicolumn{6}{|c|}{$8: 45-9: 00 / 13: 45-14: 00 / 18: 45-19: 00$} \\
\hline$L E G$ & 1 & 2 & 3 & 4 & Tot & $L E G$ & 1 & 2 & 3 & 4 & Tot \\
\hline 1 & 0 & 13 & 4 & 14 & 31 & 1 & 0 & 8 & 32 & 30 & 70 \\
\hline 2 & 26 & 0 & 8 & 33 & 67 & 2 & 6 & 0 & 15 & 10 & 31 \\
\hline 3 & 4 & 10 & 0 & 3 & 17 & 3 & 19 & 12 & 0 & 27 & 58 \\
\hline 4 & 7 & 46 & 24 & 0 & 77 & 4 & 48 & 9 & 12 & 0 & 69 \\
\hline Tot & 37 & 69 & 36 & 50 & 192 & Tot & 73 & 29 & 59 & 67 & 228 \\
\hline
\end{tabular}


After reconstructing the actual state through $\mathrm{O} / \mathrm{D}$ matrices and geometric surveys, the two "conventional" roundabout solutions were designed, which in some cases showed greater criticality than the actual state. Therefore, two "non-conventional solutions" were implemented, which instead allowed to reduce/eliminate the above-mentioned critical aspects, both from a functional and environmental point of view.

A careful analysis of the actual state has shown, for both intersections, a low level of safety especially for the execution of some maneuvers (Figures $2 b$ and $3 b$ ). By observing the planimetric configuration of the intersections, and in particular the first one, it is immediately clear that the design of a circular roundabout is very complicated because the central axes of the branches converging at the intersection are not aligned.

Therefore, a particular type of roundabout was chosen, i.e. the roundabout with "elongated" central island. In general, the use of this geometric arrangement is allowed if the ratio between the radii of the two circumferences forming the central island is between 0.75 and 1 [21]. This ratio favors the maintenance of low speeds and acceptable safety levels within the intersection. Figure 4 shows the design solutions adopted for the two intersections under study (Figures $4 \mathrm{a}$ and $4 \mathrm{~b}$ ).

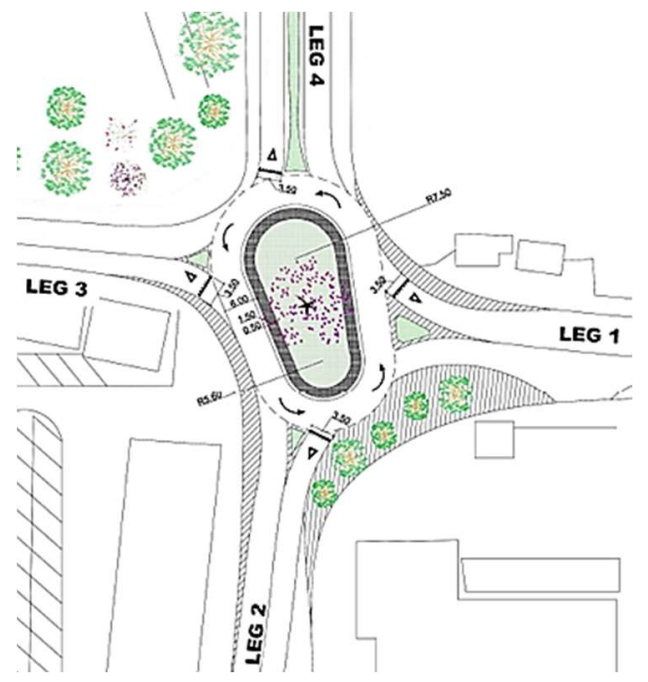

(a)

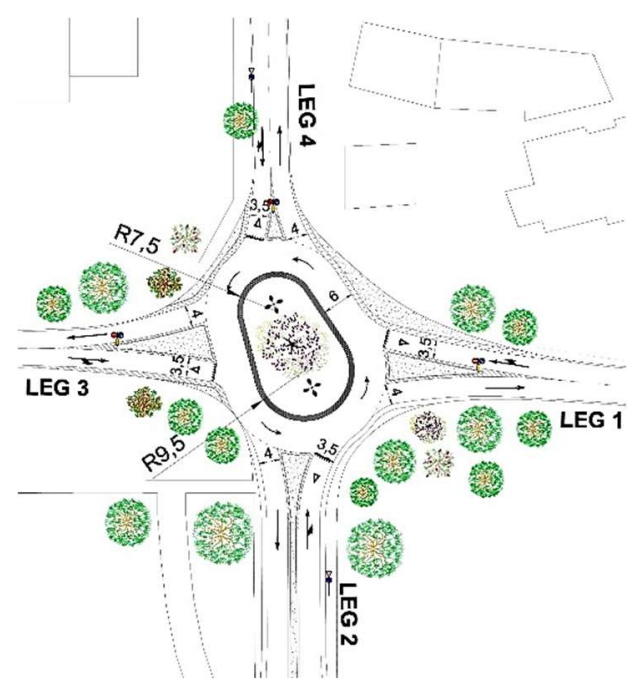

(b)

Figure 4: "Elongated" roundabout solutions.

These design solutions were used as a comparison term to assess the effectiveness of alternative solutions.

The analyses were conducted with capacity assessments based on traditional HCM [22] and CETUR [23] methods and the use of two software tools: PTV Vissim ${ }^{\circledR}[24,25]$, advanced and flexible traffic simulation software that can realistically simulate complex vehicle interactions at the microscopic level, and Autodesk Vehicle Tracking ${ }^{\circledR}$ [26], a design and analysis tool for transport infrastructure focused on swept path analysis.

Capacity analyses carried out on "elongated" schemes have shown that the intersection improves significantly compared to the current actual state. However, the methods used for the capacity calculation, which only partially take into account the actual geometrical and physical characteristics of the intersection, led to the definition of high LOS (Level of Service) levels (LOS A). As it will be highlighted later on this paper, the analyses with a micro-temporal simulator, instead, show how a LOS A, analytically calculated, may not correspond to a correct and fluid circulation. 


\subsection{Case study 1 - turbo-roundabout}

As already highlighted in the previous paragraph, the intersection is mainly subject to light traffic currents; therefore, an unconventional scheme (turbo-roundabout) has been implemented to improve the outflow conditions, with relatively higher speeds but always in safe conditions.

Following international Standards (Section 2), the spiral and all the boundary elements such as the separation kerbs of the lanes were built. Once defined $\mathrm{R}$ equal to $4.20 \mathrm{~m}$ and radius $\mathrm{R}_{1}$ equal to $10.50 \mathrm{~m}$, it was possible to obtain the other radii necessary for the turbine construction (i.e. $\mathrm{R}_{2}$ equal to $14.70 \mathrm{~m}$ and $\mathrm{R}_{3}$ equal to $18.90 \mathrm{~m}$ as in Section 2). For the design of the central island, a spiral shape with a surmountable area was chosen to facilitate the inscription of 5-axle vehicles at the roundabout (Figure 5). Figures 6a and $6 \mathrm{~b}$ show two microsimulation moments of the unconventional design solution.

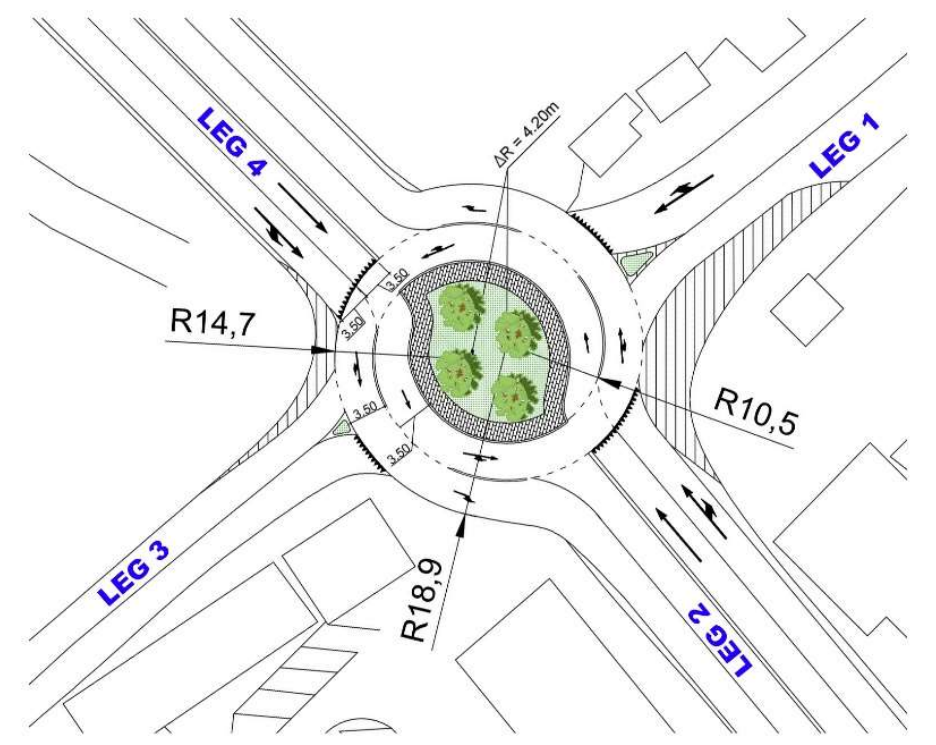

Figure 5: Intersection 1 - Turbo-roundabout design.

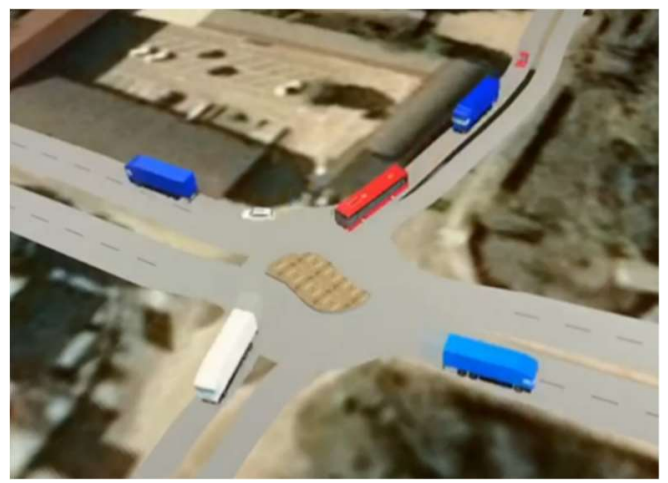

(a)

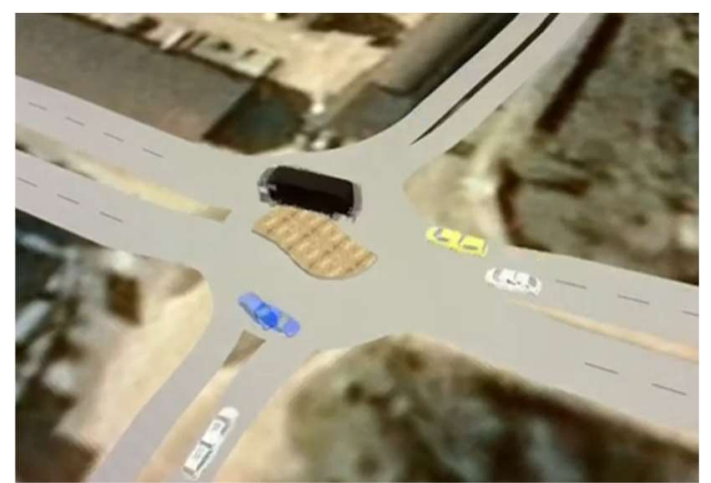

(b)

Figure 6: Turbo-roundabout microsimulation.

The calibration of the microsimulation models was conducted only for the actual state of intersections. For this purpose, the detection data of the traffic flows supported also by video recordings were used. In particular, it was possible to evaluate the dynamic 
parameters (speed, queues, etc.) from the videos. The calibration parameters remained unchanged in subsequent simulations. The calibration process is a crucial aspect for the reliability of the model but the importance of calibration cannot be over emphasized [27]. Recent tests of six different software packages found that calibration differences of 13 percent in the predicted freeway speeds for existing conditions increased to differences of 69 percent in the forecasted freeway speeds for future conditions [28]. Other authors, such as Brockfeld et al. [29] used nonlinear optimization in order to calibrate parameters of different simulation models to traffic data from a test region. They found that the average error between simulated and real data was about $16 \%$ [30].

The calibration of microsimulation models for unconventional roundabout schemes, given the complexity of the problem, can only be done ex-post with a sufficient level of reliability. That is, creating a provisional configuration of the intersection on which to monitor circulation. However, in this case, the objective of the work is to evaluate, on equal conditions, the benefits that unconventional roundabout schemes can produce compared to leaving the intersection as it is or using an "elongated" scheme. These benefits, in comparative and not absolute terms, can be evaluated leaving the calibration parameters unchanged between the microsimulation model of the actual state and that of the unconventional solution.

Table 3 shows the microsimulation results in terms of average speed and travel time for each single manoeuvre. The actual state shows extremely low speeds and travel times that in some cases reach almost 25 seconds per 100 meters. The "elongated" solution shows a worsening trend compared to the actual situation considering that, for some manoeuvres, the travel time exceeds 25 seconds. The turbo-roundabout shows a limited increase in travel speeds and a significant reduction in travel times of less than 15 seconds.

Table 3: Intersection 1- microsimulation results.

\begin{tabular}{ccccccc}
\hline & \multicolumn{3}{c}{ Actual state } & \multicolumn{2}{c}{ "Elongated" solution } & \multicolumn{2}{c}{ Turbo-roundabout } \\
\cline { 2 - 7 } PATH & $\begin{array}{c}\text { Vaverage } \\
(\mathrm{km} / \mathrm{h})\end{array}$ & $\begin{array}{c}\text { Travel } \\
\text { time }\end{array}$ & $\begin{array}{c}\text { Vaverage } \\
(\mathrm{s})\end{array}$ & $\begin{array}{c}\text { Travel } \\
\text { time } \\
(\mathrm{km} / \mathrm{h})\end{array}$ & $\begin{array}{c}\text { Vaverage } \\
(\mathrm{s})\end{array}$ & $\begin{array}{c}\text { Travel } \\
\text { time } \\
(\mathrm{km} / \mathrm{h})\end{array}$ \\
\hline $1-2$ & 18.74 & 19.20 & 26.09 & 13.79 & 27.54 & 13.07 \\
$1-3$ & 19.85 & 18.13 & 30.41 & 11.84 & 32.41 & 11.10 \\
$1-4$ & 19.14 & 18.80 & 23.00 & 15.64 & 28.14 & 12.79 \\
$2-1$ & 23.28 & 15.46 & 26.66 & 13.50 & 32.84 & 10.96 \\
$2-3$ & 24.34 & 14.78 & 32.88 & 10.94 & 29.20 & 12.32 \\
$2-4$ & 24.34 & 14.78 & 29.24 & 12.31 & 28.10 & 12.81 \\
$3-1$ & 17.18 & 20.95 & 16.04 & 22.44 & 24.75 & 14.54 \\
$3-2$ & 18.45 & 19.51 & 13.16 & 27.36 & 27.45 & 13.11 \\
$3-4$ & 15.01 & 23.99 & 13.46 & 26.74 & 26.82 & 13.42 \\
$4-1$ & 16.88 & 21.32 & 19.42 & 18.54 & 27.42 & 13.12 \\
$4-2$ & 19.49 & 18.47 & 17.33 & 20.77 & 32.14 & 11.20 \\
$4-3$ & 22.25 & 16.17 & 18.36 & 19.61 & 29.33 & 12.27 \\
\hline
\end{tabular}

Table 4 shows, for each solution considered, the parameters related to the queues analysis:

- AQL (Average Queue Length) - the current queue length is measured upstream every time step. From these values the arithmetical average is computed for each time interval. 
- MQL (Maximum Queue Length) - the current queue length is measured upstream every time step. From these values, the maximum is computed for each time interval.

- NS (Number of Stops) - number of stops within queue: total number of events when a vehicle enters the queue condition.

Table 4: Intersection 1- queues results.

\begin{tabular}{cccccccccc}
\hline & \multicolumn{3}{c}{ Actual state } & \multicolumn{3}{c}{ "Elongated" solution } & \multicolumn{3}{c}{ Turbo-roundabout } \\
\cline { 2 - 9 } Leg & $A Q L$ & $M Q L$ & $N S$ & $A Q L$ & $M Q L$ & $N S$ & $A Q L$ & $M Q L$ & $N S$ \\
& $(m)$ & $(m)$ & & $(m)$ & $(m)$ & & $(m)$ & $(m)$ & 7 \\
\hline 1 & 1.04 & 91.39 & 17 & 2.00 & 101.19 & 10 & 2.55 & 12.11 & 5 \\
2 & 0.34 & 27.75 & 9 & 0.09 & 11.96 & 25 & 5.12 & 12.42 & 1 \\
3 & 1.75 & 90.11 & 61 & 25.72 & 148.12 & 46 & 3.54 & 11.34 & 4 \\
4 & 0.71 & 60.38 & 32 & 18.88 & 111.34 & 47 & 4.05 & 16.59 & 4 \\
\hline
\end{tabular}

The microsimulation highlights the total inefficiency of the current circulation scheme, which gives rise to long queues (MQL). The introduction of the "elongated" roundabout does not bring substantial benefits. Instead, the turbo-roundabout drastically improves circulation both in terms of maximum queue length (MQL) and number of stops (NS).

Table 5 shows the parameters that define the overall performance of the intersection.

In detail, the Average Delay Time (ADT) is the average time loss per vehicle equal to the ratio between the total delay and the sum of the number of vehicles at the intersection and those arrived (Average Delay Time per vehicle $[\mathrm{s}]=$ total delay time / [active + arrived vehicles]), while the Average Number of Stops (ANS) per vehicle is equal to the ratio between the total number of stops and the sum of the number of vehicles at the intersection and those arrived (Average Number of Stops per vehicle $=$ Total number of stops / [active + arrived vehicles]).

Table 5: Intersection 1- global intersection performance.

\begin{tabular}{llccccc}
\hline & & Actual state & $\begin{array}{c}\text { "Elongated" } \\
\text { Solution }\end{array}$ & $\begin{array}{c}\text { Variation } \\
\%\end{array}$ & $\begin{array}{c}\text { Turbo- } \\
\text { roundabout }\end{array}$ & $\begin{array}{c}\text { Variation } \\
\%\end{array}$ \\
\hline Average Delay Time & $(\mathrm{s})$ & 15.89 & 32.57 & 51.21 & 9.60 & -39.58 \\
Average speed & $(\mathrm{km} / \mathrm{h})$ & 22.00 & 18.61 & -15.41 & 25.02 & 12.07 \\
Average Number of Stops & $(\%)$ & 78.28 & 81.56 & 4.19 & 27.12 & -65.36 \\
Total stops & & 1142 & 916 & -19.79 & 309 & -72.94 \\
\hline
\end{tabular}

The intersection performance confirms the ineffectiveness of the "elongated" solution compared to the turbo-roundabout, with delay time (ADT) almost halved compared to the actual situation, percentage of stops (ANS) reduced to one third against a slight increase in average travel speeds.

The analysis was completed with verification of the overall dimensions of commercial vehicles (5-axle articulated trucks with a length of $16.50 \mathrm{~m}$ and $12 \mathrm{~m}$ buses) along the intersection engagement trajectories (swept path analysis) conducted with the aid of Autodesk Vehicle Tracking ${ }^{\circledR}$ software. These analyses highlighted the full dimensional compatibility of the turbo-roundabout for the circulation of these vehicles. Figures $7 \mathrm{a}$ and $7 \mathrm{~b}$ show two examples of use of Autodesk Vehicle Tracking ${ }^{\circledR}$ software. The figures shows only a demonstration example of swept path analysis. 


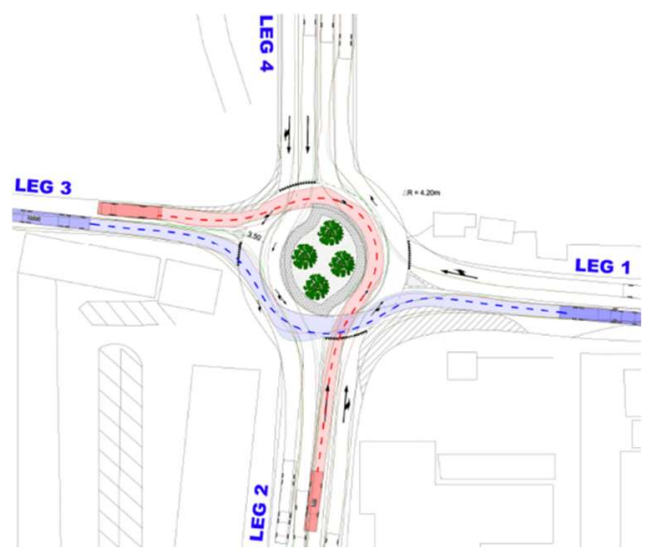

(a)

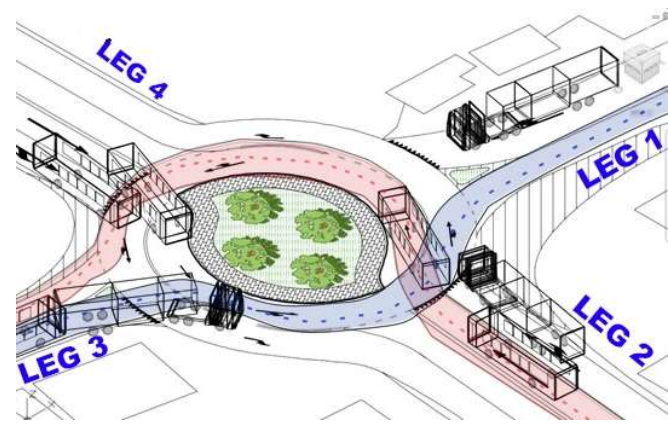

(b)

Figure 7: Intersection 1- Autodesk Vehicle Tracking ${ }^{\circledR}$ swept path analysis.

\subsection{Case study 2 - flower-roundabout}

The intersection is subject to heavy vehicular traffic throughout the day due to the presence of industrial activities (Section 3). Therefore, the most effective scheme is the flower-roundabout which, due to the "depressed" lanes, allows for an easier evacuation of heavy vehicle currents when turning right.

The design solution is characterized by a circular central island with a radius of $8.50 \mathrm{~m}$ of which $1.5 \mathrm{~m}$ can be surmounted. The outer radius of the roundabout ring is $14.50 \mathrm{~m}$ with a transverse section of $6.0 \mathrm{~m}$ (Figures 8 and 9) while the "depressed" lanes have a cross section of $4.00 \mathrm{~m}$.

As in the previous case, Table 6 shows the results of microsimulation for the actual state and the two design solutions. The "elongated" solution does not show particular improvements with respect to the actual state. The flower-roundabout shows a limited increase in speed and a significant reduction in travel time, which is on average less than 15 seconds.

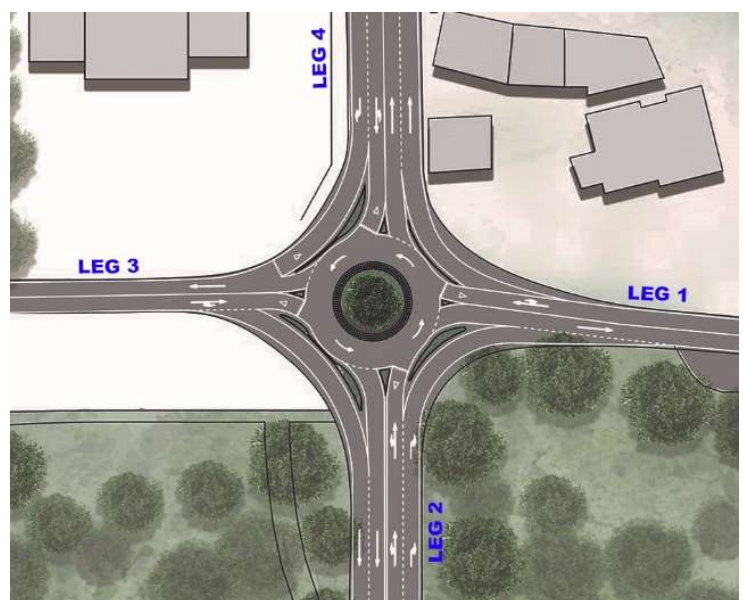

(a)

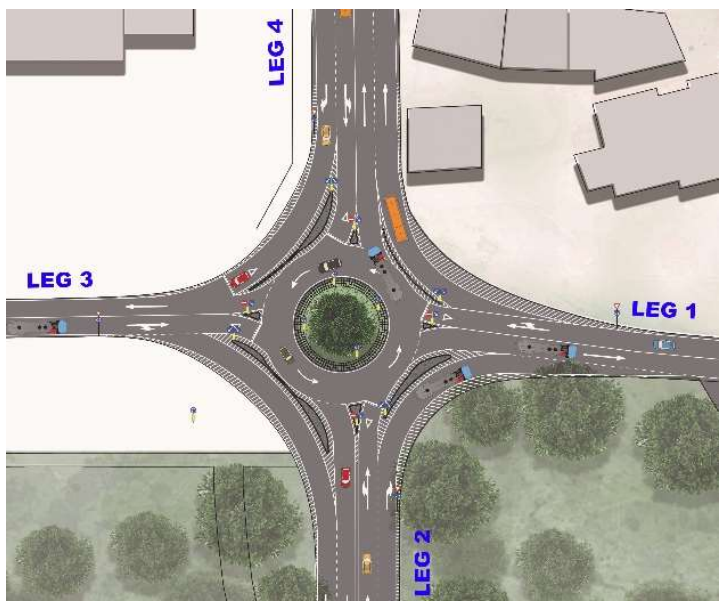

(b)

Figure 8: Intersection 2 - flower-roundabout solution. 
Figure 9: Intersection 2 - flower-roundabout design.

Table 6: Intersection 2 - microsimulation results.

\begin{tabular}{|c|c|c|c|c|c|c|}
\hline \multirow[b]{2}{*}{ PATH } & \multicolumn{2}{|c|}{ Actual state } & \multicolumn{2}{|c|}{ "Elongated" solution } & \multicolumn{2}{|c|}{ Flower-roundabout } \\
\hline & $\begin{array}{c}V_{\text {average }} \\
(\mathrm{km} / \mathrm{h})\end{array}$ & $\begin{array}{c}\text { Travel } \\
\text { time } \\
\text { (s) }\end{array}$ & $\begin{array}{c}V_{\text {average }} \\
(\mathrm{km} / \mathrm{h})\end{array}$ & $\begin{array}{c}\text { Travel } \\
\text { time } \\
\text { (s) }\end{array}$ & $\begin{array}{c}V_{\text {average }} \\
(\mathrm{km} / \mathrm{h})\end{array}$ & $\begin{array}{c}\text { Travel } \\
\text { time } \\
(s)\end{array}$ \\
\hline $1-2$ & 16.66 & 21.61 & 20.68 & 17.41 & 26.10 & 13.79 \\
\hline $1-3$ & 17.43 & 20.65 & 24.41 & 14.75 & 23.68 & 15.21 \\
\hline $1-4$ & 17.91 & 20.11 & 21.41 & 16.82 & 27.54 & 13.07 \\
\hline $2-1$ & 14.57 & 24.71 & 18.66 & 19.29 & 22.69 & 15.86 \\
\hline $2-3$ & 18.13 & 19.86 & 21.90 & 16.44 & 22.61 & 15.92 \\
\hline $2-4$ & 16.90 & 21.30 & 17.46 & 20.62 & 24.66 & 14.60 \\
\hline $3-1$ & 17.24 & 20.88 & 22.14 & 16.26 & 27.87 & 12.92 \\
\hline $3-2$ & 19.18 & 18.77 & 20.82 & 17.29 & 27.16 & 13.26 \\
\hline $3-4$ & 16.07 & 22.40 & 23.35 & 15.42 & 26.29 & 13.69 \\
\hline $4-1$ & 13.82 & 26.05 & 19.60 & 18.36 & 26.48 & 13.60 \\
\hline $4-2$ & 16.96 & 21.22 & 13.09 & 27.49 & 25.77 & 13.97 \\
\hline $4-3$ & 21.21 & 16.97 & 18.98 & 18.97 & 27.23 & 13.22 \\
\hline
\end{tabular}

The microsimulation highlights the total inefficiency of the current circulation scheme and especially of the "elongated" solution that generates queues (MQL) of excessive length (Table 7). The flower-roundabout significantly improves circulation both in terms of maximum queue length (MQL) and number of stops (NS).

Table 7: Intersection 2 - queues results.

\begin{tabular}{cccccccccc}
\hline & \multicolumn{3}{c}{ Actual state } & \multicolumn{3}{c}{ "Elongated" solution } & \multicolumn{3}{c}{ Flower-roundabout } \\
\cline { 2 - 10 } Leg & $A Q L$ & $M Q L$ & $N S$ & $A Q L$ & $M Q L$ & $N S$ & $A Q L$ & $M Q L$ & $N S$ \\
& $(m)$ & $(m)$ & & $(m)$ & $(m)$ & & $(m)$ & $(m)$ & \\
\hline 1 & 1.24 & 29.66 & 15 & 2.31 & 27.92 & 79 & 0.05 & 1.26 & 0 \\
2 & 0.86 & 9.52 & 18 & 7.28 & 38.43 & 146 & 0.22 & 6.00 & 11 \\
3 & 0.59 & 5.87 & 6 & 0.44 & 4.62 & 14 & 0.13 & 4.84 & 2 \\
4 & 1.62 & 32.64 & 34 & 9.54 & 52.64 & 186 & 0.19 & 6.45 & 8 \\
\hline
\end{tabular}


The intersection overall performance (Table 8) shows, also in this case, the ineffectiveness of the "elongated" solution compared to the flower-roundabout with a half-time loss (ADT), percentage of stops (ANS) reduced to one tenth and a slight increase in average travel speeds compared to the actual state.

The verification of the dimensions of commercial vehicles along the intersection engagement trajectories (swept path analysis) have shown the full dimensional compatibility of the flower-roundabout for the circulation of these vehicles (Figure 10).

Table 8: Intersection 2 - global intersection performance.

\begin{tabular}{|c|c|c|c|c|c|c|}
\hline & & Actual state & $\begin{array}{c}\text { "Elongated" } \\
\text { solution }\end{array}$ & $\begin{array}{c}\text { Variation } \\
\% \\
\end{array}$ & $\begin{array}{c}\text { Flower- } \\
\text { roundabout }\end{array}$ & $\begin{array}{c}\text { Variation } \\
\% \\
\end{array}$ \\
\hline Average Delay Time & (s) & 21.21 & 18.26 & -13.91 & 9.60 & -54.74 \\
\hline Average speed & $(\mathrm{km} / \mathrm{h})$ & 17.17 & 20.21 & 17.71 & 25.67 & 27.02 \\
\hline Average Number of Stops & $(\%)$ & 72.57 & 84.26 & 16.11 & 7.11 & -90.20 \\
\hline Total stops & & 821 & 948 & 15.47 & 82 & -90.01 \\
\hline
\end{tabular}

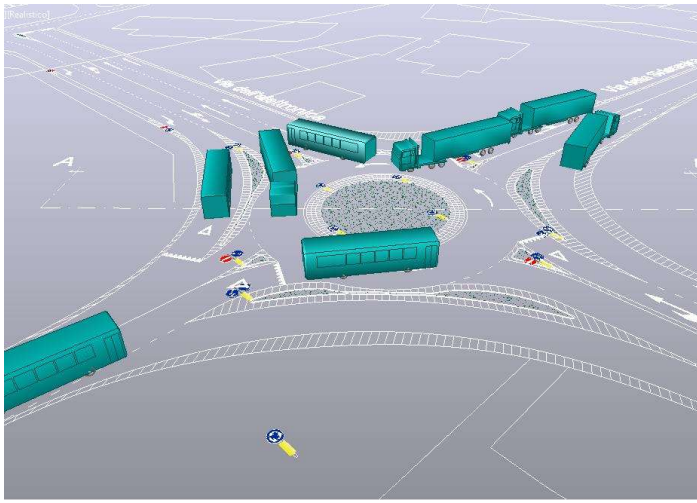

(a)

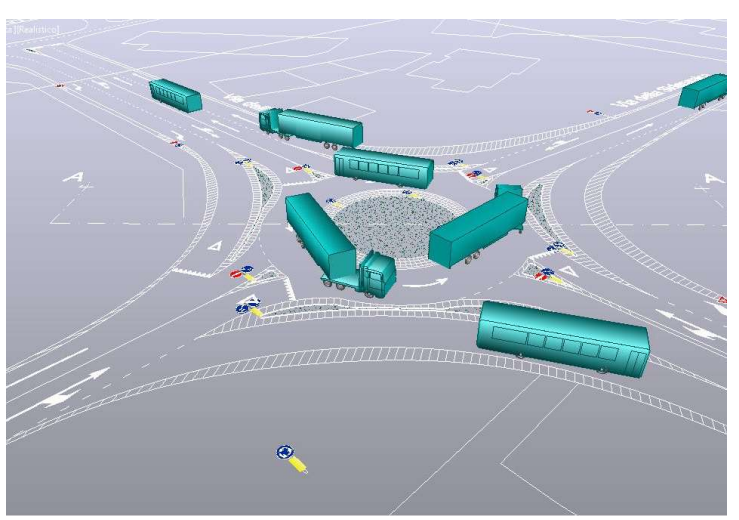

(b)

Figure 10: Intersection 2 - Autodesk Vehicle Tracking ${ }^{\circledR}$ swept path analysis.

For this second case study, the effectiveness of the flower-roundabout was evaluated also from an environmental point of view by estimating the amount of emissions into the atmosphere generated by vehicle traffic.

The assessment of emissions is limited to the comparison of different design schemes. In other words, the evaluation does not claim to assess in absolute terms the annual amount of pollutant emissions but only wants to compare the different solutions considering the same traffic flows on the corresponding legs and varying only the travel speeds as obtained by microsimulation.

The comparative study was carried out on the emissions of pollutants referred to the actual state and the two design solutions. In this case, the following pollutants were analysed:

- $\mathrm{CO}$ carbon monoxide;

- $\mathrm{CO}_{2} \quad$ carbon dioxide;

- $\mathrm{NO}_{\mathrm{x}} \quad$ nitrogen oxides;

- $\mathrm{PM}_{10}$ particulate matter.

The pollutant assessment study was carried out using the COPERT software [31] for the determination of specific emission factors. The used methodology is consistent with literature [32]. The evaluation of emissions was carried out taking into account a set of parameters such as average speed, flow of circulating vehicles and travel distance. The 
Average Daily Traffic required by COPERT has been defined by multiplying the mean traffic flows (Table 1) by 8 hours. It should be noted that for the comparative assessment of emissions it is completely irrelevant to define the ADT strictly.

The assessment of pollutant emissions has been distinguished for the four legs of the intersection. The results obtained are shown leg by leg according to the three states of analysis (Figure 11). It is worth mentioning that the quantification of the produced emissions is the starting input for the estimation of the monetary value of the externalities in transport and that many European countries have selected and collected the methodologies to be used for this purpose in specific guidelines [33].

The results allow to evaluate the total loads of the main pollutants examined and their variability according to the solution examined.

Compared to the actual situation, the conventional solution shows an average emission reduction for all the pollutants considered of the order of $10 \%$. The emissions decrease, but not excessively, this is due to the queues that form in the roundabout legs and the stop-and-go phenomena.

Due to the increase in average speeds and the reduction in queues, the flowerroundabout, conversely, allows a reduction in emissions of $20 \%$ on average.

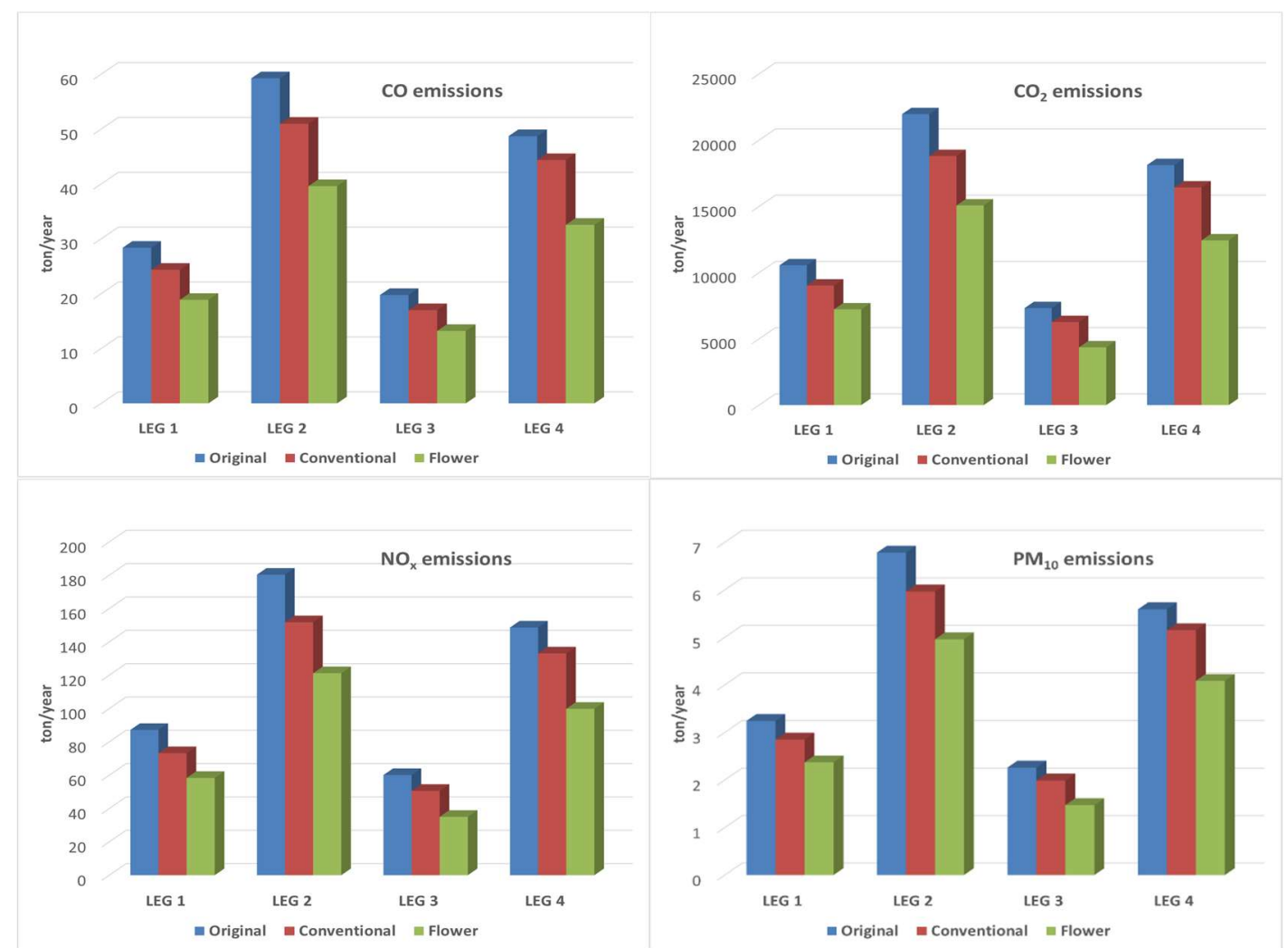

Figure 11: Intersection 2 - pollutant emissions in the hypothesis adopted.

\section{Conclusions}

The paper proposed the use of non-conventional roundabouts, such as turboroundabouts and flower roundabouts, for the reduction/solution of both functional and safety criticality of two road intersections located in suburban areas. 
The purpose of the work is to evaluate in comparative and not absolute terms, also through the use of simplified design parameters, the effectiveness of non-conventional schemes with respect to the actual state of intersections or the use of conventional "elongated" roundabout schemes.

This objective can be achieved through the use of a methodology that implements techniques of microsimulation of vehicle traffic and swept path analysis. The results, in this specific case, confirm the effectiveness of non-conventional roundabout schemes in improving traffic parameters and traffic safety.

The contribution of the paper is to have proposed a simplified methodology of comparison between alternative design schemes able to qualitatively highlight their benefits and to guide the road designer in the choice of the potential solution. Subsequently, the identified scheme may be subject to further in-depth analysis aimed at the objective and precise quantification of the operating parameters.

\section{Author Contributions}

All authors contributed equally to the research and the writing of this manuscript.

\section{References}

http://www.turboroundabout.com Date of access: 3 March 2020, TORUS ${ }^{\circledR}$ software, Transoft Solutions B.V.

Tollazzi, T., Renčelj, M. (2014) "Modern and Alternative Types of Roundabouts - State of the Art" - Proceedings from the 9th International Conference "Environmental Engineering”, Vilnius, Lithuania, eISSN 2029-7092, eISBN 978-609-457-640-9, doi: http://dx.doi.org/10.3846/enviro.2014.137.

Džambas, T., Ahac, S., Dragčević, V. (2016) “Geometric Design of Turbo Roundabouts According to Croatian and Dutch Guidelines". Proceedings from the 4th International Conference on Road and Rail Infrastructure "CETRA 2016", (S. Lakušić ed.), Šibenic, Croatia, ISSN 1848-9850, https://master.grad.hr/cetra/ocs/index.php/cetra4/cetra2016/paper/viewFile/510/355.

Bondzio, L. (2014) "Experiences with Turbo-Roundabouts in Germany"- Proceedings from the 5th Rural Roads Design meeting, Copenhagen, Denmark, $\mathrm{https}: / / \mathrm{nmfv}$.dk/rural-roads-design-meeting-no-5-april-3rd-to-4th-2014.

Anagnostopoulos, A., Kehagia, F. (2018) "Turbo-Roundabouts as an Alternative to Roundabouts in Terms of Traffic Safety, Capacity and Pollutant Emissions"Proceedings from the 7th Pan-hellenic Road Safety Conference, Larissa, Greece.

Macioszek, E. (2015) "The Road Safety at Turbo Roundabouts in Poland", The Archives of Transport 33 (1), pp. 57-67, doi: 10.5604/08669546.1160927.

FHWA (2019) "Turbo Roundabouts", Informational Primer, https://safety.fhwa.dot.gov/intersection/innovative/roundabouts/docs/fhwasa20019.p df.

Engelsman, J. C., Uken, M. (2007) "Turbo Roundabouts as an Alternative to Two Lane Roundabouts"- Proceedings from the 26th Southern African Transport Conference (SATC 2007), Pretoria, South Africa, pp. 581-589. ISBN: 1-920-01702-X.

Murphy, T. (2015) "The Turbo Roundabout a First in North America"- Proceedings from the TAC Conference \& Exhibition, Charlottetown, PEI.

Fortuijn, L. G. H. (2009) "Turbo Roundabouts: Design Principles and Safety Performance", Journal of the Transportation Research Board, 2096, pp. 16-24, doi: 10.3141/2096-03. 
Mauro, R., Guerrieri, M. (2013) "Flower Roundabouts: Performances Analysis and Comparison with Conventional Layouts", European Journal of Scientific Research, 94 (2), pp. 242-252.

Tollazzi, T., Renčelj, M., Turnsek, S. (2011) "New Type of Roundabout: Roundabout with Depressed Lanes for Right Turning - Flower Roundabout", PROMETTraffic\&Transportation, 23 (5), pp. 353-358, doi: 23. 10.7307/ptt.v23i5.153.

Tollazzi T., Renčelj M., Turnšek S. (2010) "Roundabout with Depressed Lanes for Right Turnings-Flower Roundabout"- Proceedings from the XVII International Scientific Symposium on Transport Systems, Opatija (Croatia).

CROW (2008) “Turborotondes (Turbo roundabouts)", Publicatie 257, Dutch Technology Platform for Transport, Infrastructure and Public Space, Netherlands (in Dutch).

Ministry of Transport Republic of Slovenia (2011) "Roundabouts with a Spiral Course of the Circulatory Roadway". TSC 03.XXX, draft version.

FGSV (2014) "Advisefor Turboroundabouts), draft version.

Serbian Authority for Roads (2012) "Manual for Road Design in Republic of Serbia, Part 5.3 Roundabouts), Beograd.

Croatian Authority for Roads (2014) "Guidelines for Design of Roundabouts with spiral Circulatory Roadway on State Roads", Zagreb.

Giuffrè, O., Guerrieri, M., Granà, A. (2010) "Turbo-roundabout general design criteria and functional principles: case studies from real world"-Proceedings from the IV International Symposium on Highway Geometric Design TRB (Transportation Research Board), Valencia, Spain.

Džambas, T., Ahac, S., Dragčević, V. (2017) “Geometric Design of Turbo Roundabouts" Tehnički vjesnik - Technical Gazette, doi: 24. 309-318. 10.17559/TV20151012162141.

Canale, S., Distefano, N., Leonardi, S., Pappalardo G. (2011) "Progettare le RotatorieTecniche per la progettazione e la verifica delle intersezioni a circolazione rotatoria secondo il D.M. 19/04/2006", 2nd Edition, ISBN: 978-88-6310-322-9.

TRB - Transportation Research Board (2000) "Highway Capacity Manual-Special Report 209”, National Research Council, Washington, USA.

CETUR - Centre d'Etudes des Transports Urbains (1988) "Conception des Carrefours à sens Giratoire Implantés en Milieu Urbain”, Ministère de l'Equipment, du Logement, de l'Amenagement du Territoire et des Transports.

https://www.ptvgroup.com/en/solutions/products/ptv-vissim/ Date of access: 5 March 2020, PTV Group.

https://www.et.byu.edu/ msaito/CE662MS/Labs/VISSIM 530 e.pdf Date of access: 4 March 2020, VISSIM 5.30-05 User Manual, PTV Planung Transport Verkehr AG, 2011.

https://www.autodesk.com/products/vehicle-tracking/overview/ Date of access: 5 March 2020, AutoCad ${ }^{\circledR}$ software, Autodesk.

Dowling Associates Inc., Cambridge Systematics, Inc. (2003) "Volume III-Guidelines for Applying Traffic Microsimulation Modeling Software", Final Report prepared for Federal Highway Administration, Oakland, California.

Bloomberg, L., Swenson, M., Haldors B. (2003) "Comparison of Simulation Models and the Highway Capacity Manual" - Proceedings from the 82nd Annual Meeting of the Transportation Research Board, Washington, D.C. 
Brockfeld, E., Kühne, R.D., Skabardonis, A., Wagner, P. (2003) "Towards a benchmarking of microscopic traffic flow models", TRB, Transportation Research Record Journal of the Transportation Research Board, Washington D.C.

Olstam, J.J., Tapani, A. (2004) "Comparison of Car-following models", working paper VTI meddelande 960A. Title of project: Development of the VTI rural traffic simulation model and Simulated traffic for the VTI driving simulator, Swedish National Road and Transport Research Institute, Linköping, Sweden. ISSN: 03476049.

https://www.emisia.com/utilities/copert Date of access: 5 March 2020, Copert, Emisia Copert.

Agostinacchio, M., Ciampa, D., Diomedi, M., Olita, S. (2014) "The Management of Air Pollution from Vehicular Traffic by Implementing Forecasting Models", In: CRC Press 2014-Taylor \& Francis Group (eds) Sustainability, Eco-efficiency, and Conservation in Transportation Infrastructure Asset Management, London, Great Britain.

Petruccelli, U., (2015) “Assessment of external costs for transport project evaluation: Guidelines in some European countries", Environmental Impact Assessment Review, 54-2015, 61-7. doi: 10.1016/j.eiar.2015.05.004. 